\title{
Achalasia Cardia: A Mimicker of Pulmonary Tuberculosis in a High-Burden Setting
}

\author{
Pratibha Sharma ${ }^{1}$ Ranganath T. Ganga ${ }^{2, \odot}$ \\ 1Department of Microbiology, All India Institute of Medical Sciences \\ Raipur, Raipur, Chhattisgarh, India \\ ${ }^{2}$ Department of Pulmonary Medicine, All India Institute of Medical \\ Sciences Raipur, Raipur, Chhattisgarh, India
}

\begin{abstract}
Address for correspondence Ranganath T. Ganga, MD, Department of Pulmonary Medicine, All India Institute Of Medical Sciences Raipur, D Block 1st Floor Gate No. 4, All India Institute of Medical Sciences, Tatibandh, GE Road, Raipur 492099, Chhattisgarh, India (e-mail: ranganathtg@aiimsraipur.edu.in).
\end{abstract}

J Health Allied Sci ${ }^{\mathrm{NU}}: 2021 ; 11: 54-56$

\begin{abstract}
Keywords

- achalasia cardia

- cough

- pulmonary

tuberculosis

- weight loss

BRICS (Brazil, Russia, India, China, and South Africa) countries account for more than two-thirds of the global tuberculosis burden. Tuberculosis is a common diagnosis in patients presenting with chronic respiratory symptoms in these high-burden countries, which results in other diseases being missed easily. The national tuberculosis elimination program encourages to start antitubercular treatment on a clinical basis even without any confirmatory evidence. This has resulted in missing many nontuberculosis cases and unnecessarily exposing to adverse effects of antitubercular drugs. Here we report one such instance where achalasia cardia was missed for a long time.
\end{abstract}

\section{Introduction}

A 32-year-old lady, homemaker, presented to pulmonary medicine outpatient department with complaints of cough with yellowish expectoration, fever, loss of appetite for the past 2 weeks, and breathlessness for 5 days. On further questioning patient revealed that she has had similar episodes in the past 6 years, which used to resolve with antibiotics and symptomatic treatment, but only to recur after few weeks. She had no history of diabetes mellitus, hypertension, or any long-term medication. At presentation she was tachypneic and was maintaining a normal room air saturation. Respiratory system examination revealed coarse crackles in both the lung fields. Rest of the systemic examination was within normal limits. A presumptive diagnosis of lower respiratory tract infection (LRTI) was made. Hence, she was started on broad spectrum of antibiotics as per prevailing guidelines, and patient improved clinically. Sputum for acid-fast bacillus was negative on two consecutive occasions. Rest of her routine blood chemistry and complete blood counts were within normal limits. Chest skiagram (chest X-ray [CXR]) posteroanterior view was done as part of routine evaluation ( - Fig. 1), which showed mediastinal widening with air fluid level. This prompted us to go for contrast-enhanced computed tomography (CECT) of thorax ( - Fig. 2), which showed dilated esophagus with narrowing of the lower end of the esophagus suggestive of achalasia cardia. Thus, the patient was referred to gastroenterology center where upper gastrointestinal endoscopy and esophageal manometry clinched the diagnosis of achalasia cardia.

\section{Discussion}

Air fluid level in the CXR is a common finding in daily clinical practice, but diagnosis is not always easy. It can be due to both pulmonary and extrapulmonary causes. Common differential diagnosis includes lung abscess, bronchiectasis, infected bulla, loculated pleural effusion, cystic teratoma, ${ }^{1}$ bronchogenic cyst, ${ }^{2}$ hydatid cyst, pancreatic pseudocyst, ${ }^{3}$ esophageal perforation, published online December 2, 2020
DOI https://doi.org/

10.1055/s-0040-1721541

ISSN 2582-4287. (c) 2020. Nitte (Deemed to be University).

This is an open access article published by Thieme under the terms of the Creative Commons Attribution-NonDerivative-NonCommercial-License, permitting copying and reproduction so long as the original work is given appropriate credit. Contents may not be used for commercial purposes, or adapted, remixed, transformed or built upon. (https://creativecommons.org/licenses/by-nc-nd/4.0/).

Thieme Medical and Scientific Publishers Pvt. Ltd. A-12, 2nd Floor, Sector 2, Noida-201301 UP, India 


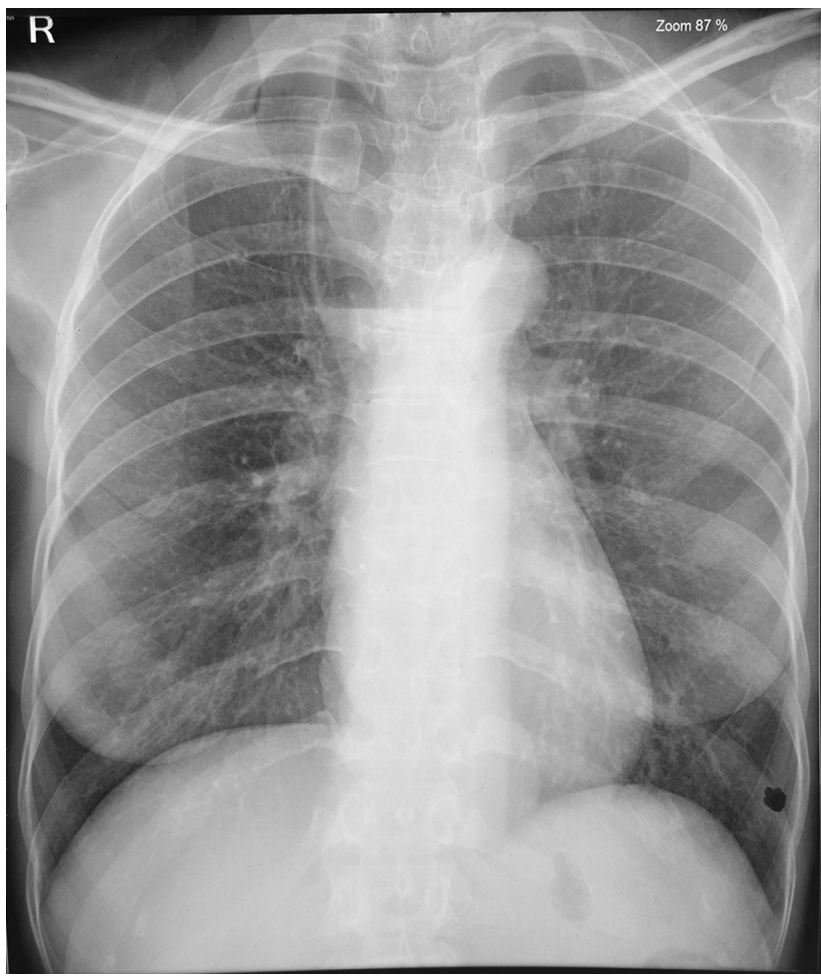

Fig. 1 CXR PA view showing mediastinal widening with airfluid level in the midline. CXR PA, chest X-ray posteroanterior.

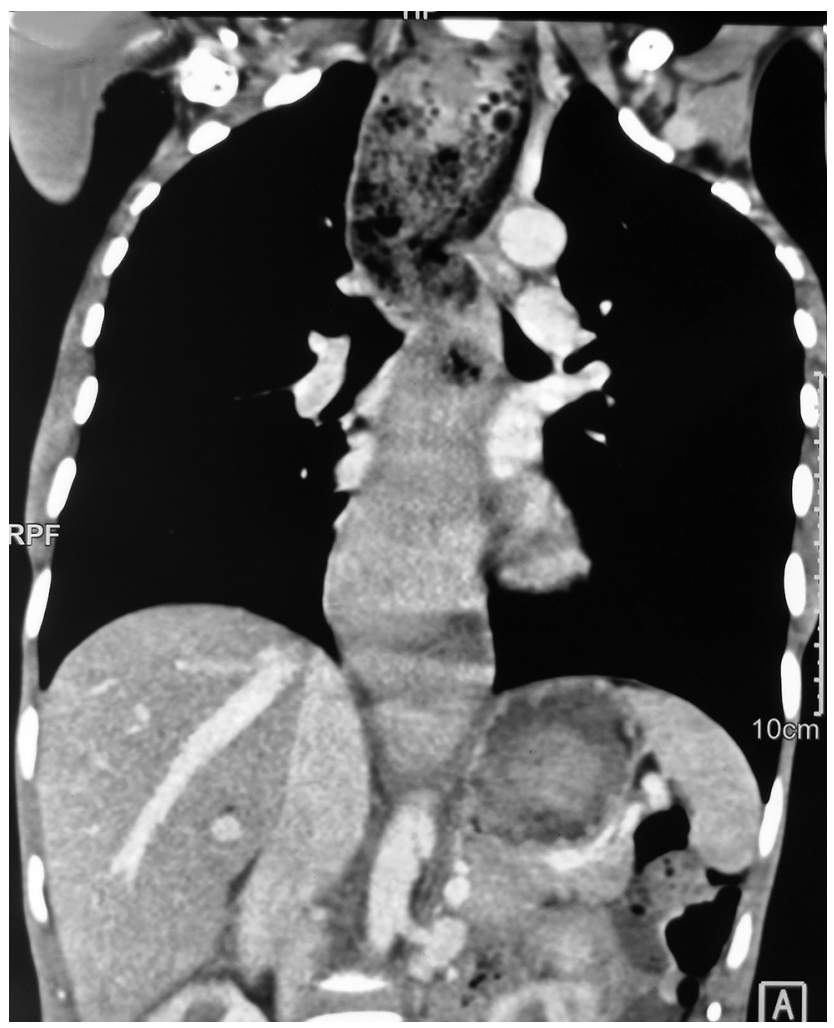

Fig. 2 CECT thorax coronal reformation showing grossly dilated esophagus with food debris. CECT, contrast-enhanced computed tomography.

communication of mediastinum with trachea or esophagus, and infection with gas-forming organism like Escherichia coli,
Proteus, Pseudomonas, Klebsiella, Clostridium, Acinetobacter, Candida, or Cryptococcus. ${ }^{4}$ Megaesophagus or esophageal dilatation is caused by esophageal stricture, Chagas disease, fibrosing mediastinitis, progressive systemic sclerosis, and achalasia cardia, but achalasia cardia causes the most severe dilatation. ${ }^{5}$

Achalasia cardia is a rare primary motor disorder of the esophagus and lower esophageal sphincter (LES), characterized by insufficient relaxation of the LES and aperistalsis of esophagus. It occurs with a frequency of 1 in 100,000 people and has no sex or racial predilection. Incidence peaks around 30 to 40 years of age. The exact etiology remains unknown, but is probably due to inflammatory trigger by autoimmune, viral, or neurodegenerative origin,${ }^{6}$ leading to degeneration of inhibitory neurons in the esophageal myenteric plexus. In a classical setting, dysphagia for both solids and liquids with regurgitation of bland undigested food with retrosternal chest pain during meals should point toward evaluation for achalasia cardia. ${ }^{6}$ Diagnosis is clinched by aperistalsis, bird beak appearance, poor emptying of barium into stomach on barium swallow, and endoscopy showing dilated esophagus with saliva, liquid, and undigested food particles with absence of stricture or tumor in the esophagus. Esophageal manometry shows aperistalsis and incomplete LES relaxation with no mechanical obstruction. ${ }^{7}$

Achalasia cardia is classified into type- 1 (classical achalasia), type-2 (achalasia with compression and pressurization changes), and type-3 (spastic achalasia). This classification helps in management decisions. ${ }^{8}$ Medical management includes use of calcium channel blockers, but the main stay of management is the pneumatic balloon dilatation and laparoscopic myotomy. Treatment success at 2 years for pneumatic dilatation is $86 \%$ and $90 \%$ for laparoscopic Heller's myotomy. ${ }^{9}$ These patients are at risk of aspiration pneumonia as a result of natural course of the disease and $10 \%$ develop megaesophagus needing esophagectomy; there is also a 50-fold increase in the risk of squamous cell carcinoma of the esophagus. ${ }^{10}$

Our patient had no classical symptoms like dysphagia and chest pain, but had repeated episodes of LRTI, which could be due to repeated episodes of aspiration. She had constitutional symptoms like loss of appetite, which is present in achalasia cardia but in tuberculosis also, which prompted us to evaluate for tuberculosis due to high burden of disease in the country, which turned out to be negative. CXR picture prompted us to go for CECT thorax, which later helped us in making the diagnosis of achalasia cardia.

\section{Conclusion}

Mediastinal air fluid levels can be affected due to myriad of etiologies ranging from anerobic infections to congenital anomalies to structural lung disorders. Pulmonary tuberculosis is a common diagnosis among patients with recurrent LRTIs in high-burden settings. Computerized tomogram of thorax should always be considered when in dilemma, as esophageal disorders can mimic tuberculosis. 


\section{Conflict of Interest}

None declared.

\section{References}

1 Fulcher AS, Proto AV, Jolles H. Cystic teratoma of the mediastinum: demonstration of fat/fluid level. Am J Roentgenol 1990;154(2):259-260

2 Choi JE, Lim S, Park CR, Cha HJ, Kwon W-J. Foregut duplication cyst: a novel computed tomography finding mimicking a small bowel hernia: a case report. Medicine (Baltimore) 2017;96(50):e9184

3 Mathew M, Narula MK, Anand R. Pancreatic pseudocyst of the mediastinum. Indian J Radiol Imaging 2002;12(3):353-354

4 Ahmad M, Dakshinamurty KV. Emphysematous renal tract disease due to Aspergillus fumigatus.J Assoc Physicians India 2004; 52:495-497

5 Fraser RS, Muller NL, Coleman N, PPD. Diagnosis of Diseases of the Chest. 4th edition. Philadelphia: WB Saunders and Co.; 1999 2966-2967
6 Vaezi MF, Richter JE; American College of Gastroenterology Practice Parameter Committee. Diagnosis and management of achalasia. Am J Gastroenterol 1999;94(12):3406-3412

7 Vaezi MF, Pandolfino JE, Vela MF. ACG clinical guideline: diagnosis and management of achalasia. Am J Gastroenterol 2013;108(8):1238-1249, quiz 1250

8 Bredenoord AJ, Fox M, Kahrilas PJ, Pandolfino JE, Schwizer W, Smout AJ; International High Resolution Manometry Working Group. Chicago classification criteria of esophageal motility disorders defined in high resolution esophageal pressure topography. Neurogastroenterol Motil 2012;24(Suppl 1) :57-65

9 Boeckxstaens GE, Annese V, des Varannes SB, et al; European Achalasia Trial Investigators. Pneumatic dilation versus laparoscopic Heller's myotomy for idiopathic achalasia. N Engl J Med 2011;364(19):1807-1816

10 Dunaway PM, Wong RK. Risk and surveillance intervals for squamous cell carcinoma in achalasia. Gastrointest Endosc Clin N Am 2001;11(2):425-434, ix 